\title{
Evaluation of the Contribution of Aerosols in the Contamination of the Environment in the Greater Casablanca
}

\author{
HADER Khadija ${ }^{1}$ and Lahcen BAHI ${ }^{2}$ \\ 1. Research Laboratory for the Quality of Air and the Water, Section of Environment, Mohammadia School of Engineers (EMI), \\ B.P.765 Agdal, Rabat, Morocco \\ 2. The Responsible of the Applied Geophysics Laboratory, the Engineering Geology, and the Environment, Mohammadia School of \\ Engineers (EMI), B.P.765 Agdal, Rabat, Morocco
}

\begin{abstract}
The Greater Casablanca, like the other large cities, has experienced significant urban and industrial development in recent years, this development has certainly helped develop the productive fabric, generate significant employment opportunities for hundreds of thousands of families, but at the expense of the mobility and quality of the environment particularly those of the air. The deterioration of the air quality affects more and more the population's health with significant cost and damage to the community, this study aims to quantify the degree of aerosols pollution damage and also its health effects.
\end{abstract}

Key words: The Greater Casablanca, air pollution, aerosols.

\section{Nomenclature}

GSP large point sources

SAMIR Moroccan limited company of the refining industry

SLIN linear sources

SSURF surface sources

\section{Introduction}

The Greater Casablanca is experiencing an alarming problem of deteriorating air quality due to its high human and economic concentration [1], the region covers an area of about $1,208 \mathrm{~km}^{2}$ representing $0.17 \%$ of the total area of the Kingdom. It includes nine district prefectures of Casablanca (Casablanca-Anfa, Mers Sultan El Fida, Ain Sebaa Hay Mohammadi, Sidi Bernoussi, Sidi Othmane, Moulay Rachid, Ain Chock, Ben M'Sick Hay Hassani) the Pachlik Mechouar, the prefecture of Mohammedia, and the two provinces of Médiouna and Nouacer. These two last are divided into five urban municipalities and 10

Corresponding author: HADER Khadija, engineer, research fields: geographic information systems, the air quality, the water quality and medical waste. rural municipalities [2].

\section{Sampling Sites}

\subsection{Casablanca}

CHU: The station is funded by the Greater Casablanca and is installed in University Hospital Center "IbnRushd". It is a type of urban station;

ONCF: The station is funded by the Greater Casablanca region and is installed within the industrial district Ain Sbaâ, it is an industrial nearby;

SIDI OTHMANE: The station is acquired under the Qualit'Air program installed in the neighborhood Sidi Othman. It is a type of urban station;

EL JAHID: The station is installed in the college "El Jadid" located in a residential area. It is an urban resort;

EL WILAYA [3]: Acquired as part of the Moroccan-Monegasque cooperation, it is located in the city center, in an air conditioned cabin placed in the public park in front of the willaya. It is a traffic type. 
Environment in the Greater Casablanca

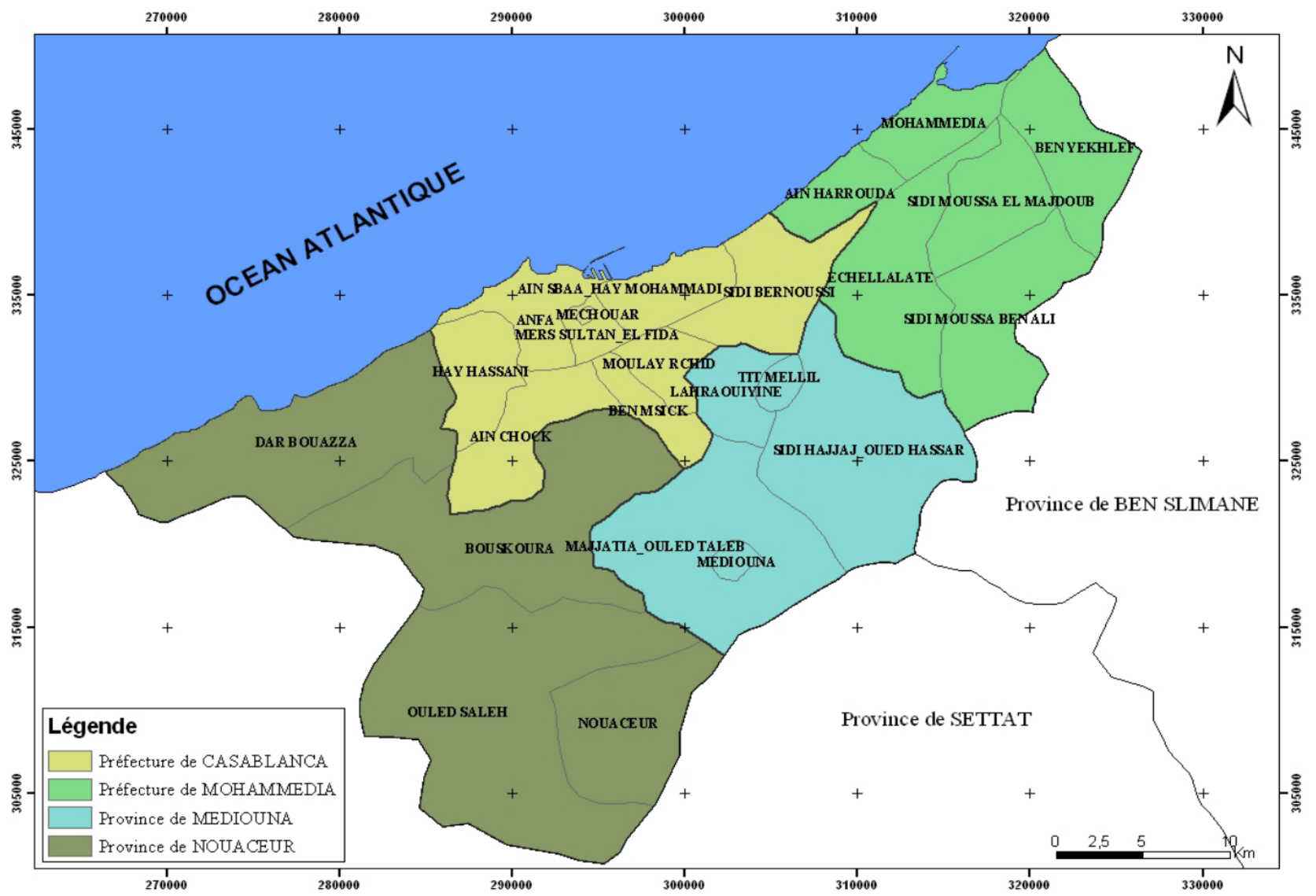

Fig. 1 The administrative division of the Greater Casablanca.

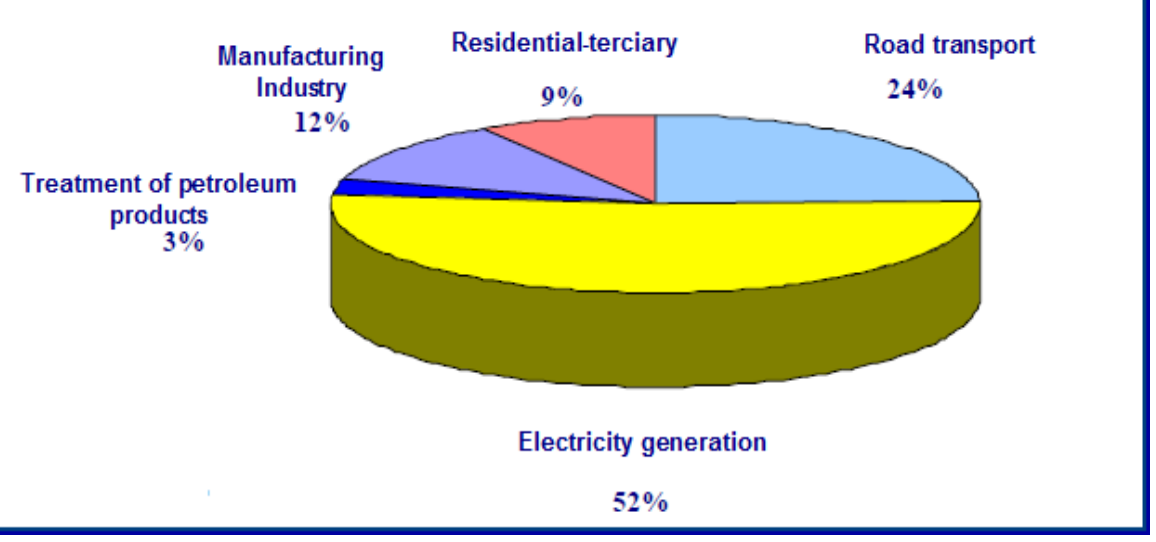

Fig. 2 Distribution of aerosol emissions in the Greater Casablanca.

\subsection{Mohammedia}

PREFECTURE: It is installed at the headquarters of the prefecture industrial type;

ELKHANSAA: It is installed in a school; the location of the station location gives it the character of an urban station.

\section{Results}

3.1 The Distribution of Aerosols Emissions by Sector of Activity [4]

The distribution of aerosols emissions by sector shows that the electricity generation sector is the largest emitter sector in these aerosols in the RGC. Its share 


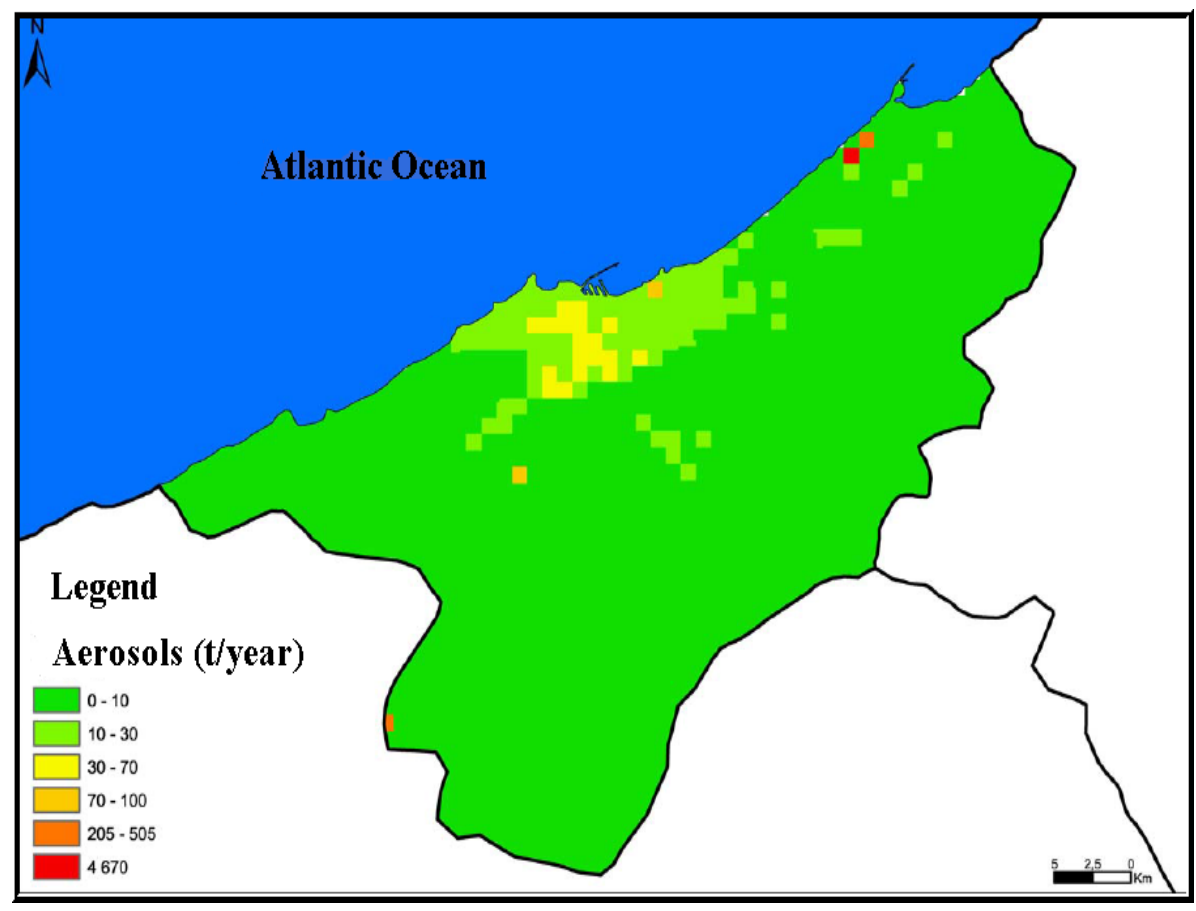

Fig. 3 Total emission of aerosol in the Greater Casablanca.

of global emissions in the region is $52 \%$. The road transport sector is second with a contribution of $25 \%$.

The manufacturing sector is responsible for $12 \%$ of total emissions of aerosols which $8 \%$ is generated by industrial processes and $4 \%$ is related to combustion. Only $12 \%$ of aerosol emissions come from heating equipment in the tertiary sector (9\%) and refinery SAMIR (2\%).

\subsection{Distribution of Aerosols Emissions by Source} Category [5]

- Emissions from large point sources (GSP):

The large point sources are the main emitters of particles in the region. They are responsible of the emission of 620 tons of the aerosols and thus represent about $63 \%$ of total emissions in the region.

- Emissions of the linear sources (SLIN) [6]:

SLIN emissions, estimated at about 710 tons of particles account for only $8 \%$ of total emissions of the area.

- Emissions from surface sources (SSURF):

The SSURF are the second aerosol issuers in the region. They represent approximately $29 \%$ of total emissions of the region, 91\% of emissions SSURF are rejected at the city of Casablanca, $5 \%$ by Mohammedia (5\%) and $4 \%$ by other municipalities in the region. The high share of SSURF emissions recorded at the city of Casablanca is explained by the density the diffuse urban traffic in the main district prefectures Casablanca (Anfa, Ain Sebaa-Hay Mohammadi, Mer-Sultan El Fida, Ain Chock, etc.), and the importance of the diffuse industrial fabric [7].

\section{Conclusions}

The amount of aerosols emitted in the Greater Casablanca amounted to 8,900 tons $92 \%$ is due to fuel combustion and fuel and $8 \%$ for industrial processes [8].

The town of Mohammedia, home of the most energy-intensive industrial units in the region (CTM SAMIR) dismissed about 5,030 tons of aerosols, or $56 \%$ of total emissions of the region. The emissions of Casablanca prefectural districts were estimated at 2,960 tons of aerosols representing $33 \%$ of total emissions in the region. The contribution to the total emissions of aerosols common provinces Mediouna 
Environment in the Greater Casablanca

and Nouacer is $9 \%$ which comes from about $6 \%$ of cement kilns [9].

\section{References}

[1] KARIOUN, A. 1997. Moroccan Journal of Civil Engineering Special Environment 68: 42-3.

[2] The Economic and Social Development Plan of the Greatest Casablanca, 2014.

[3] ADEME. 1998. Air Pollution n 164-Octobre December 1999.

[4] Baklanov, A. et al. 2007. "Integrated Systems for Forecasting Urban Meteorology, Air Pollution and Population Exposure." Atmospheric Chemistry and Physics 7: 855-74.

[5] Brucher, W., Kessler, C., Kerschgens, M., and Ebel, A. 2000. "Simulation of Traffic-Induced Air Pollution on Regional to Local Scales." Atmospheric Environment 34
(27): 4675-81.

[6] Air Emissions Inventory of the Greatest Casablanca. Ministry of Energy, Mines, Water and Environment; Department of Environment, March 2009.

[7] Byun, D., and Ching, J. 1999. Science Algorithms of the EPA Models-3 Community Multiscale Air Quality (CMAQ) Modelling System. U.S. Environmental Protection Agency, Tech. rep., EPA/600/R-99/030 (NTIS PB2000-100561), Washington, D.C.

[8] Longley, P. A., Goodchild, M. F., Maguire, D. J., and Rhind, D. W. 2001. Geographic Information Systems and Science. New York: John Wiley \& Sons.

[9] Rebolj, D., and Sturm, P. J. 1999. "A GIS Based Component-Oriented Integrated System for Estimation, Visualization and Analysis of Road Traffic Air Pollution." Transport and Air Pollution-8th International Symposium, 15-21. 